JRIT

14,2

Received 17 September 2019 Accepted 25 November 2019

\section{Positive aspects of disability among college students}

\author{
Jessica L. Sniatecki \\ Department of Healthcare Studies, The College at Brockport, \\ SUNY, Brockport, New York, USA \\ Jennifer Randhare Ashton \\ Department of Education and Human Development, The College at Brockport, \\ SUNY, Brockport, New York, USA \\ Holly B. Perry \\ The College at Brockport, SUNY, Brockport, New York, USA, and \\ Linda H. Snell \\ Department of Nursing, The College at Brockport, \\ SUNY, Brockport, New York, USA
}

\begin{abstract}
Purpose - The number of students with disabilities pursuing a college education has increased dramatically in recent years (Hall and Belch, 2000; Hitchings et al., 2011; Horn et al., 2006; Retish and Horvath, 2005; Snyder et al., 2016; Stodden et al., 2001), yet, evidence suggests that these students continue to encounter significant challenges and barriers that may have a dramatic effect on their college experience (Madaus and Shaw, 2006; Sniatecki et al., 2015; Stodden et al., 2001). The paper aims to discuss this issue.

Design/methodology/approach - Positive experiences and aspects of being a college student with a disability have not garnered as much consideration and have received little attention in the professional literature to date. The current study sought to address this gap through examination of positive aspects of disability among 12 undergraduate students. Data were gathered via qualitative interviews.

Findings - Results included five distinct themes related to students' experiences: personal growth and selfacceptance; empathy/understanding; advocacy and teaching others; unique relationship experiences and opportunities; and drive/determination/perseverance.

Research limitations/implications - The implications of these themes and future directions for research on positive aspects of disability are also addressed.

Originality/value - The results of this study provide support for the social model of disability as a lens to view individuals with disabilities as complete people who, with their impairments, can and do go on to lead positive and meaningful lives.
\end{abstract}

Keywords Disability, College students, Positive aspects of disability

Paper type Research paper

The number of students with disabilities pursuing a college education has increased dramatically in recent years (Hall and Belch, 2000; Hitchings et al., 2005; Horn et al., 2006; Raue and Lewis, 2011; Snyder et al., 2016; Stodden et al., 2001). Despite the rising numbers, evidence suggests that students with disabilities continue to encounter significant challenges and barriers that may have a dramatic effect on their college experience (Madaus and Shaw, 2006; Sniatecki et al., 2015; Stodden et al., 2001). With so much attention being paid to obstacles, the positive experiences and aspects of being a college student with a disability have not

(C) Jessica L. Sniatecki, Jennifer Randhare Ashton, Holly B. Perry and Linda H. Snell. Published in Journal of Research and Innovative Teaching \& Learning. Published by Emerald Publishing Limited. This article is published under the Creative Commons Attribution (CC BY 4.0) licence. Anyone may reproduce, distribute, translate and create derivative works of this article (for both commercial and non-commercial purposes), subject to full attribution to the original publication and authors. The full terms of this licence may be seen at http://creativecommons.org/licences/by/4.0/legalcode
Journal of Research in Innovative Teaching \& Learning Vol. 14 No. 2, 2021 pp. $150-161$ Emerald Publishing Limited 2397-7604

DOI 10.1108/JRIT-09-2019-0069 
garnered as much consideration and have received little attention in the professional literature to date. The lack of research in this area might be related to the traditional reliance upon a deficit, or medical, model of disability.

Deficit, or medical, models of disability label the natural variations that occur in human shape, ability, and behavior as "disabilities" and identify these impairments to be problematic personal deficiencies that are in need of remediation or cure. The medicalization of disability characterizes people with disabilities as being sick, impaired or otherwise abnormal and in need of treatment to bring them to the realm of normalcy (DasGupta, 2015). This perspective has resulted in differential and unequal treatment of people with disabilities that is largely rationalized and justified by the belief that they are inherently deficient (Baynton, 2013). These deficit models highlight the individual challenges and negative impacts of impairment, while leaving limited space for an individual with a disability to be considered whole and have positive experiences (Shakespeare, 2013). The widespread prominence of a medical or deficit model of disability likely has contributed to the lack of research on the positive aspects of disability in a person's life. This study seeks to use qualitative methods to explore the positive experiences of college students who identify as having disabilities using an alternative perspective that is grounded in a social model of disability.

A social model of disability recognizes that individuals with impairments can, and often do, live complete and meaningful lives and have positive experiences because of, not in spite of, their impairment. Disability, when considered through this lens, is constructed through the interpretation of the meaning of a particular impairment within a particular social, cultural, or political context (Gallagher et al., 2014). When considering disability through a social model lens, rather than a deficit-based lens, the experiences that people with disabilities have in their lives may be framed from a competent, whole, and strength-based perspective.

There has been some recent research that supports the use of a social model of disability to recognize the positive aspects of disability that emerge in a person's life which focuses on the development of a positive disability identity (Dunn and Burcaw, 2013). Much like race, class, gender, and sexual orientation, disability functions for many as an identity that marks an individual as a member of a group. When individuals are able to make sense of their disabilities within the context of their lives and find benefits that are associated with these disabilities, the personal meaning attached to the disability supports the development of a positive disability identity.

Born with hands and an arm that would be commonly considered abnormal, Rosemarie Garland-Thomson (2018) describes how it wasn't until later in her life when she came out of the 'closet' (p. 18) as disabled and began to accept herself as a complete person. For GarlandThomson, "becoming disabled" (p. 19) requires that one learn to live effectively as a person with disabilities, not live as a disabled person striving to become non-disabled. She further challenges people with disabilities to move from places of isolation to community, from ignorance to knowledge of self, from exclusion to access, and from shame to pride (GarlandThomson, 2018). The concept of disability pride is where this study on the positive aspects of disability seeks to contribute to the literature. To that end, this study recognizes the wholeness of individuals with disabilities and emphasizes the benefits and strengths of a social model of disability.

This analysis considers the lived experiences of people with disabilities using three different frameworks including disability studies, positive psychology, and post-traumatic growth. Disability studies are a theoretical perspective that critiques the traditional deficit/medical models, while promoting a social model of disability that shifts the focus from how impairment hinders an individual to how an individual with an impairment is hindered by society. Disability studies promote a social model of disability that considers individuals with disabilities as members of an oppressed community who are negatively impacted by pervasive ableism, prejudice and an overall lack of accessibility within society (DasGupta, 2015). 
JRIT

14,2

152

As a field, positive psychology focuses on the positive aspects of individuals' experiences and characteristics in an effort to fulfill "promises to improve quality of life and prevent the pathologies that arise when life is barren and meaningless" (Seligman and Csikszentmihaly, 2014, p. 279). "Positive Psychology's keynote contribution to the study of disability and rehabilitation entails directing researchers and practitioners to the aim of building, reinforcing and extending disabled individuals' strengths and capacities in order to optimize their functioning in all areas of life, and thereby promote wellness" (Naidoo, 2006, p. 595). Thus, the current study sought to address a gap in the literature through examination of positive aspects of disability among undergraduate students.

When disability emerges from a life-altering traumatic event an individual sometimes experiences a change in the way that they perceive themselves within the context of their lives. This transformation is referred to in the literature as Post Traumatic Growth (PTG) and typically involves an individual reporting positive personal changes in the following areas: new possibilities, relating to others, personal strength, appreciation of life and spiritual change (Barskova and Oesterreich, 2009; Chun and Lee, 2008; Meyerson et al., 2011). Previous research has suggested that the experience of living with disabilities may have positive implications, particularly in terms of finding meaning/purpose in life and experiencing personal growth (Salick and Auerbach, 2006; Shessel and Reiff, 1999; Weitzner et al., 2011).

Salick and Auerbach (2006) conducted qualitative interviews with ten individuals with visible impairments due to illness or injury. "Nearly all participants also spoke of finding a personal meaning in their disability, which allowed them to make sense of their new circumstances and feel a sense of purpose" (p. 1031). Further, they found that participants made a conscious decision to move forward and draw upon an inner strength to help them get through the challenges that they faced in their lives. This process includes "reevaluation of negative self-perceptions related to disability, developing a future orientation, and developing perceived control over one's illness or disability" (Salick and Auerbach, 2006, p. 1022). On an individual level, participants sought to find ways to "feel some control over an experience that was otherwise negative and uncontrollable" (p. 1031). The authors also reported that participants engaged in cognitive reframing in the "Choosing to Go On" stage of their model of PTG following medical trauma.

It is important to note that not everyone who experiences a traumatic event displays PTG and the cited research has focused primarily on the characteristics and profiles of those who do. However, this may be a salient consideration in examining the experience (both positive and negative) of some individuals with disabilities, specifically those who may have acquired disability through a traumatic event, rather than those who are born with disability or acquire it developmentally. This concept has received limited support, specifically for those with acquired physical disabilities (Elliott et al., 2002), such as spinal cord injury (SCI) (Pollard and Kennedy, 2007) and limb amputation (Oaksford et al., 2005).

Recognizing physical disability emerging from SCI presents a unique experience that the social model of disability does not adequately address, Weitzner et al. (2011) studied the personal experiences of 52 individuals with SCI. In this study, they utilized a three-level framework for understanding the positive ways that disability impacted participants' lives: self, peers, and the disability community. At the self-level, participants described advocating for themselves, experiencing personal growth, recognizing new talents and pursuing new hobbies, finding satisfaction through work, and obtaining benefits that people without disabilities did not have access to, such as preferential treatment. They described disability as "a catalyst for self-discovery and self-improvement" (Weitzner et al., 2011, p. 1461). At the peer level, respondents described providing support and education, and "using their disability positively to help other individuals living with disabilities" (p. 1461). Finally, at the disability community level, participants described giving back through involvement in disability organizations, public education, and advocacy. This included lobbying efforts and 
serving on boards and committees. They advocate for a shift to disability-positive research that pushes the boundaries of conventional deficit-based disability research.

Little is known about positive aspects of disability among college students, as there is minimal information in the literature in this area of inquiry. Consistent with the deficit model of disability, the vast majority of existing literature focuses on limitations and barriers relevant to this population (Madaus and Shaw, 2006; Stodden et al., 2001). Indeed, no published study to date has specifically examined the positive aspects of the experience of post-secondary students with disabilities. In addition, there has been a call for research that shifts the focus away from challenges and limitations to focus more on strengths and assets.

\section{Positive aspects of disability}

\section{Methodology \\ Participants}

Participants included 12 students at a public university in upstate New York. A sample size between 8 and 15 participants is recommended for the data analysis method chosen for this study (Hill et al., 1997). Participants' ages ranged from 18 to 50, with a median age of 22. Six students (50 percent) identified themselves as juniors, five ( 41.7 percent) identified as seniors, and one (8.3 percent) identified as a freshman. Each participant self-identified as being a student with a disability (SWD). The sample included students with learning disabilities, mental health disabilities and physical disabilities. A summary of participant demographics and reported disabilities is provided in Table I.

\section{Instrument}

Data were gathered through in-depth interviews using an interview protocol that examined various aspects of the college experience of SWD. The purpose of this approach was to develop a rich understanding of the students' thoughts and experiences related to disability. "At the root of in-depth interviewing is an interest in understanding the lived experience of other people and the meaning that they make of that experience" (Seidman, 2006, p. 9).

\begin{tabular}{|c|c|c|c|c|}
\hline & Age & Year in college & Employment status & Reported disabilities \\
\hline 1 & 22 & Junior & Full time & Learning disabilities (reading and writing) \\
\hline 2 & 21 & Senior & Part time & $\begin{array}{l}\text { Post-Traumatic stress disorder } \\
\text { Bipolar disorder } \\
\text { Obsessive-compulsive disorder } \\
\text { Trichotillomania } \\
\text { Gastroesophageal reflux disease }\end{array}$ \\
\hline 3 & 23 & Senior & Part time & Spina Bifida \\
\hline 4 & 24 & Junior & Unemployed & $\begin{array}{l}\text { Attention deficit disorder } \\
\text { Bipolar disorder }\end{array}$ \\
\hline 5 & 22 & Junior & Unemployed & Non-verbal Learning Disability \\
\hline 6 & 28 & Senior & Part time & $\begin{array}{l}\text { Attention deficit hyperactivity disorder } \\
\text { Tourette's syndrome } \\
\text { Obsessive-compulsive disorder }\end{array}$ \\
\hline 7 & 21 & Senior & Part time & Dyslexia \\
\hline 8 & 18 & Freshman & Unemployed & Underdeveloped muscles in hand (orthopedic disability) \\
\hline 9 & 21 & Senior & Part time & $\begin{array}{l}\text { Attention deficit hyperactivity disorder } \\
\text { Irritable bowel syndrome }\end{array}$ \\
\hline 10 & 21 & Junior & Part time & Cerebral palsy \\
\hline 11 & 26 & Junior & Unemployed & $\begin{array}{l}\text { Asperger's disorder } \\
\text { Depression and anxiety symptoms }\end{array}$ \\
\hline 12 & 50 & Junior & Unemployed & Complications due to two strokes \\
\hline
\end{tabular}

Table I. Participant characteristics 
JRIT

14,2

The results presented here are based on two questions from the interview: What are the main ways that disability impacts your life? and What are the most positive ways that your disability has affected you?

\section{Procedures}

All study procedures were reviewed and approved by the Institutional Review Board (IRB). Participants were recruited via an e-mail sent by the director of the campus disability services office. Data were gathered using an interview protocol developed by the research team, which had three members, based on the existing literature and previous research by the primary investigator. Participants met with one member of the research team who reviewed the purpose of the study, the rights of participants, and confidentiality. Each student who agreed to take part in the study signed an informed consent document acknowledging his/her intent to participate. The interviews were audio-recorded and transcribed, and each lasted approximately $60 \mathrm{~min}$. Though the interviews focused on a variety of areas related to the experience of living with a disability, this report emphasizes the data that related to positive aspects of disability.

The interview data were analyzed for themes related to the positive aspects of disability using the Consensual Qualitative Research (CQR) method (Hill et al., 1997). The recorded interviews were transcribed, and the three-person research team reviewed the transcripts, marking passages in the text that appeared noteworthy. The passages were then grouped into tentative categories based on thematic content by each reviewer independently. Next, the research team searched for "connecting threads and patterns among the excerpts within those categories and for connections between the various categories" (Seidman, 2006, p. 125). This process is inductive, with conclusions being drawn from the data (participants' words) rather than beginning with predetermined hypotheses or theories to be tested (Hill et al., 1997). The research team then reviewed the individually identified categories and the data in each category in an effort to synthesize and interpret the most salient themes related to positive aspects of disability, revisiting the interview transcripts to ensure that conclusions were accurate. Finally, an auditor reviewed the consensus categories to ensure that important themes were not overlooked, as required in the CQR process (Hill et al., 1997).

\section{Results}

Analysis of the data gathered in the interviews yielded five distinct themes related to positive aspects of disability: personal growth and self-acceptance (identified by six participants); empathy/understanding (reported by five participants); advocacy and teaching others (noted by five participants); unique relationship experiences and opportunities (mentioned by five participants); and drive/determination/perseverance (identified by four participants). The threshold for identifying a thematic category was that the grouping contained quotes from at least three ( 25 percent) participants. It should be noted that all participants reported at least one positive aspect of living with disability, which is represented in the themes that follow.

\section{Personal growth and self-acceptance}

Within the theme of personal growth and self-acceptance, participants acknowledged that their disabilities had afforded them with a new perspective on life and/or themselves. This sentiment was expressed by 50 percent $(n=6)$ of respondents. Respondents noted:

I think it's given me friends, and it's given me something to be, I'm different.

I'd probably say self-growth. 
I guess they make me kind of interesting in a quirky way [.. .] Maybe we have better coping skills because we've had to deal with this more.

There are a lot of experiences that I never would have had had I not had a disability [ . . ]. There's just a lot of - not privileges - I guess privileges that I never would have gotten to take advantage of. I'm beginning to like who I am, besides the fact that I do have a disability that's annoying sometimes.

Other than that, what I said before about perspective, about my disability giving me perspective. I think that students without any disabilities at all, depending on how they're brought up, they may not have that perspective because they may never have had to thought [sic] about how this could be different for other people based on how their brain works or how their body works.

I would say it made me appreciate life a little more. Yeah. It definitely has. I will say that's probably the best thing.

These SWD reported that their disability had made them look at life in a new way and develop a higher level self-acceptance and self-appreciation. These perspectives often developed after a significant time living with the disability, and were not typically easy or quick insights after the realization that they had a disability.

\section{Empathy and understanding}

Within the theme of Empathy and Understanding, participants expressed that having an understanding of their own disabilities has allowed them to view others with more compassion and empathy. Of study participants, 41.7 percent $(n=5)$ reported positive aspects of disability in this area:

It's definitely given me a better understanding for other people who have disabilities [ . . . because I've kinda been there and I know what it's like.

That's made a better person out of me. I'm more compassionate. I'm more empathic. I'm more sensitive to different subjects. I can relate to a lot of different people. I can place myself in other people's shoes because of the life I've had to live.

Positively, I think it's made me a better person at the same time. I know it sounds kind of cheesy, but it's made me a much more understanding person.

Another positive way, I guess, is I've kind of embraced the fact that if I am this kind of nerd archetype, I might as well play to my strengths. Sometimes you have to embrace your nerdom. It also gives one a little empathy with other people who have disabilities of just various sorts. If you have a disability that causes the way you think to be fundamentally different from other people's, that gives you perspective on what they're going through, regardless of what their disability is, really.

I guess that's a positive, just being able to put myself in different perspectives and understanding where someone's coming from, you know if they're having trouble with something. "Okay, I've experienced that, too, I know what it's like. Let's try this 'cause it helped me." Like I'll be able to talk to them better and have a more open mind.

It also gives one a little empathy with other people who have disabilities of just various sorts. If you have a disability that causes the way you think to be fundamentally different from other people's, that gives you perspective on what they're going through, regardless of what their disability is, really.

SWD in this study expressed that their disability experience allowed them to better understand not only others with disabilities, but people in general. This realization seemed in some cases to lead to confidence that their background could be helpful to others. It was a way to frame their struggles with disability in a way that could help others. 
JRIT
14,2

\section{Tenacity}

Participants in this study demonstrated tenacity, and explained that having a disability has often required them to work harder than students without disabilities, and to demonstrate drive, determination, and perseverance. Four participants (33.3 percent) reported positive aspects in this area:

To me, I think it's [the disability] almost had its benefits, because it drove me to push harder. Because my mom always said, "Yes. You have something that gets in your way, but don't let that stop you [...] I probably wouldn't have ended up going to college, if I didn't have the elementary and middle school and high school teachers that had for the extended classes and stuff to push me [...].

It's definitely given me the ability to put a fire under my butt. Makes me wanna work harder. Makes me wanna prove people wrong.

Also, it's kind of put a competitive edge in me because I feel like I have to prove that, especially since I never took meds, that I have to prove that, listen, I can overcome this.

It's also given me a push to want to do more and be more and help kids out like me because there's plenty of them out there.

It seemed as though the disability experience had compelled these students to address life challenges head on, with resolve and fortitude. Pride in their achievements was evident. They had overcome several roadblocks and felt prepared for future challenges.

\section{Teaching and advocacy}

With respect to teaching/advocacy, participants shared that they sometimes assume a role where they teach others about disabilities and advocate for disability rights. This was a relevant theme in five of the interviews ( 41.7 percent). Responses included:

The biggest thing I can think of is I teach people. I love teaching people about me.

I'm a peer specialist and since I have mental disabilities, I work with people with mental disabilities to help them advocate for themselves, help them be more independent.

It's really nice when people understand me. It's really nice when I can show them what I've learned. That's another thing; I'm like a little five year old sometimes. I like to come to people and say, "Hey, look at me. Look at what I did." It's really nice, I think, for others and myself to figure out what they can learn from me and what I can learn from them. It's just really a full happiness.

I've figured out that other people have the same problem by being involved with the Students with Disabilities Office or running into people there. I realize I'm not the only person there that has the same problem. I found people that I can work with. Some people have a little bit more trouble than I do and I know that they can ask me for help, cuz they know I understand what's going on. It brought me to a new group of people that I could connect with on a different level than other friends that I talk to about music and stuff, I talk to about how they live with their disability and we trade ideas and we figure out different ways that we can try and use our disability to help ourselves and help everybody else around us.

On the more positive note, I feel like my disability has made me a stronger person. It has made a better person out of me. I advocate for people. Not just myself. I get to share my unique experiences with other people and I get to open their minds and have them understanding life isn't just pretty flowers and a sunny day.

Teaching others about disability and advocating for other SWD appeared extremely important to participants in this study and provided them with immense satisfaction and pride.

\section{Unique opportunities and experiences in relationships}

In the final theme of unique opportunities/experiences in relationships, it was revealed that students with disabilities have had unique opportunities in their lives because of their 
disabilities, and have also forged close relationships with those whom they felt they could trust. Of study participants, 41.7 percent $(n=5)$ identified that disability had a positive influence on their interpersonal relationships:

There are a lot of experiences that I never would have had had I not had a disability. I never would have had the friends that I have through - I went to a camp for kids with disabilities when I was younger. I wouldn't have met those kids.

It was a great experience to be able to finally realize that I can open myself up to people and I'm not always going to get hurt if I open myself up to people. I'm not always going to get hurt if I tell someone I have IBS or I have a learning disability. People aren't going to make fun of me for that and the people who do, not worth making friends with anyways. Learning that people could be your friend even if you're quote-unquote different, great experience for me.

My disability really doesn't change my relation to the other students. It makes it positive cuz they - it shows I'm letting them in to tell them that I have this. It's more of a connection that I trust you to understand that I have a disability and I trust you enough that you're not gonna say anything bad about it.

I've made such closer and better friends because of that. Having someone who I realized I could talk to and trust [... II feel like I've made much closer friends because I have something that they respect me enough not to tell other people. There's definitely that for the social situation.

Resoundingly, participants in this study described relationship experiences that they did not feel they would have had were it not for their disability status. Participants also communicated that the relationships they develop are based on trust and provide emotional support. While this is true for all friendships, participants expressed the feeling that their relationships are deeper than many other students' experience.

\section{Discussion}

Results clearly indicate that many of the college students with disabilities interviewed experienced and recognized positive outcomes that were directly related to their having a disability. Our findings suggest that there are commonalities in the ways that students perceive the positive aspects of having a disability, and the data imply that these positive outcomes may be relevant in student success and engagement in college life. Although the social model of disability does not purport that everyone's experiences with disability will be positive, it does situate the challenges faced by SWD as products of social, environmental, political and cultural barriers and not deficiencies or deficits of the individual. Despite the limitations or challenges the participants endure while navigating their college experiences, it is clear that they possess many positive self-perceptions and do not view themselves as being defined or confined by their disabilities. The positive sense of self and strength of identity indicated by the participants reflects the notion of individual wholeness that the social model promotes. The analysis indicates that the participants in this study recognize the ways in which their lives have been positively influenced as a result of their disability, which appears to be adaptive while promoting resilience.

Perhaps the participants' recognition of the positive aspects of disability indicated by the themes of "personal growth/self-acceptance" and "tenacity" represent a form of cognitive reframing similar to Salick and Auerbach's (2006) "Choosing to Go On" stage of PTG. These authors also reported that participants engaged in cognitive reframing in the "Choosing to Go On" stage of their model of post-traumatic growth following medical trauma. This stage involved "an existential choice about moving forward. The majority of the sample spoke of finding an inner strength, which they described as drawing on to get them through hard times" (Salick and Auerbach, 2006, p. 1029). 
JRIT

14,2

Findings from this study can also be analyzed using the three-tier framework provided by Weitzner et al. (2011). Their framework, previously described in this study can be used to understand the positive ways that disability impacted participants' lives: self, peers, and the disability community. The themes of "Personal Growth and Self-Acceptance" and "Tenacity," reflect the work of the individual at the self-level described by Weitzner et al. At the peer level, the most salient themes are "Empathy and Understanding" and "Unique Opportunities and Experiences in Relationships," particularly in terms of providing education and support to others. Finally, with an emphasis on sharing positive experiences with others, the theme of "Teaching and Advocacy" reflects engagement at the disability community level described by Weitzner et al. (2011).

The identity-based aspects of disability are also reflected in the participants' descriptions of themselves throughout all five themes. Dunn and Burcaw (2013) suggest that the use of personal narratives to share positive experiences with disability can help people with disabilities better understand themselves, develop a stronger personal sense of pride and selfworth, and form ties with the disability community. These three positive outcomes closely parallel Weitzner et al.'s (2011) framework for understanding the positive impact of disability on a person's life at the self, peer and disability community levels. The findings of this study, when considered alongside the work of Dunn and Burcaw (2013) and Weitzner et al. (2011) indicate that there is much to learn about the lives and experiences of college students with disabilities and that a social model of disability provides that lens.

The exploration of positive aspects of students' disability experience aligns with the framework of Positive Psychology as it emphasizes capabilities and strengths (Naidoo, 2006), in contrast to much of the existing literature in this area which has focused on barriers and limitations. This shift in focus has potentially positive implications, allowing an opportunity for individuals to recognize ways in which their disability experience has impacted their lives in positive and meaningful ways. This could provide opportunities for individuals to capitalize on these areas of strength to improve their overall functioning and life satisfaction.

However, caution must be used when interpreting the positive experiences of individuals with disabilities. Because of the media's tendency to portray individuals with disabilities as being courageous and determined to overcome their disability, there is often an elevation of high achieving individuals with disabilities to the status of role models. If generalized to all individuals with disabilities, this can set up unrealistic expectations for many, leaving them to feel like failures for not living up to the lofty standards of the "supercrips" (Black and Pretes, 2007).

\section{Limitations}

As is common in qualitative investigations, the main limitation in this study was sample size. Further, all participants in this study were enrolled as students at the same institution. Thus, the findings in this area are not necessarily generalizable to college students throughout the USA.

In addition, participants voluntarily self-selected into the study. It is possible that students with disabilities who did not opt to participate may have different experiences related to positive aspects of disability. It is possible that students who chose not to participate did so because they are overwhelmed and struggling to meet the needs of daily life. Finally, it is highly likely that not all students with disabilities were reached through the recruitment method used for this study, since all participants in this study were registered with the disability services office.

Though PTG was used as a component of the conceptual framework for this study, it was not directly explored in the interviews. While some participants with acquired disabilities may have experienced trauma (e.g. injury) that contributed to their 
impairment, it is unclear whether that contributed to the findings of this study. This is both a limitation and a potential area for further inquiry.

\section{Future directions}

Though the results of this study provide significant evidence that college students with disabilities recognize positive implications associated with their disability status, it also raises several lingering questions. Perhaps the most salient of these is whether recognition of the positive aspects of disability is adaptive and enhances personal adjustment. If so, then how can counselors help individuals with disabilities to recognize these positive aspects and encourage them to explore and develop them? How do we know if someone is ready for this process? Viewed holistically, the themes: personal growth and self-acceptance, empathy/ understanding, advocacy and teaching others, unique relationship experiences and opportunities, and drive/determination/perseverance reflect a balance of positive character and identity traits that most people would strive for, regardless of their disability status. Do the services typically provided by colleges and universities to students with disabilities provide support in areas that promote positive, inclusive, and empathic relationships with disabled and non-disabled peers?

Clearly, a study of this scope raises many more questions than it answers, but it also serves as a potential starting point for a multitude of future studies. The relevance of developing a positive disability identity and the influence that this might have on the success of college students should be explored in future research on positive aspects of disability. Future inquiries should explore whether type of disability influences positive experiences related to disability. Additionally, future studies could explore whether there are distinctions among those who have congenital disabilities vs those who have acquired them later in life.

Additional studies are needed to explore whether recognition of positive aspects of disability has positive implications for personal development and success as well as methods and interventions that counselors can use to assist their clients in recognizing these facets of disability experience. However, the results of this study do provide support for the social model of disability as a lens to view individuals with disabilities as complete people who, with their impairments, can and do go on to lead positive and meaningful lives.

\section{References}

Barskova, T. and Oesterreich, R. (2009), "Post-traumatic growth in people living with a serious medical condition and its relations to physical and mental health: a systematic review", Disability and Rehabilitation, Vol. 31 No. 21, pp. 1709-1733, doi: 10.1080/09638280902738441.

Baynton, D. (2013), "Disability and the justification of inequality in American history", in Davis, L.J. (Ed.), The Disability Studies Reader, Routledge, New York, NY, pp. 17-33.

Black, R.S. and Pretes, L. (2007), "Victims and victors: representation of physical disability on the silver screen", Research and Practice for Persons with Severe Disabilities, Vol. 32 No. 1, pp. 66-83.

Chun, S. and Lee, Y. (2008), "The experience of posttraumatic growth for people with spinal cord injury", Qualitative Health Research, Vol. 18 No. 7, pp. 877-890.

DasGupta, S. (2015), "Medicalization", in Adams, R., Reiss, B. and Serlin, D. (Eds), Keywords for Disability Studies, NYU Press, New York, NY, pp. 38-39.

Dunn, D.S. and Burcaw, S. (2013), "Disability identity: exploring narrative accounts of disability", Rehabilitation Psychology, Vol. 58 No. 2, pp. 148-157, doi: 10.1037/a0031691.

Elliott, T.R., Kurylo, M. and Rivera, P. (2002), "Positive growth following acquired physical disability", in Snyder, C.R. and Lopez, S.J. (Eds), The Oxford Handbook of Positive Psychology, 2nd ed., Oxford University Press, Inc., New York, NY, pp. 687-699. 
JRIT

14,2

Gallagher, D.J., Connor, D.J. and Ferri, B.A. (2014), "Beyond the far too incessant schism: special education and the social model of disability", International Journal of Inclusive Education, Vol. 18 No. 11, pp. 1120-1142, doi: 10.1080/13603116.2013.875599.

Garland-Thomson, R. (2018), "Becoming disabled", in Davis, L.J. (Ed.), Beginning With Disability: A Primer, Routledge, New York, pp. 15-19.

Hall, L.M. and Belch, H.A. (2000), "Setting the context: reconsidering the principles of full participation and meaningful access for students with disabilities", New Directions for Student Services, Vol. 91, pp. 5-17, doi: 10.1002/ss.9101.

Hill, C.E., Thompson, B.J. and Williams, E.N. (1997), "A guide to conducting consensual qualitative research”, The Counseling Psychologist, Vol. 25 No. 4, pp. 517-572.

Hitchings, W.E., Retish, P. and Horvath, M. (2005), "Academic preparation of adolescents with disabilities for postsecondary education”, Career Development for Exceptional Individuals, Vol. 28 No. 1, pp. 26-35, doi: 10.1177/08857288050280010501.

Horn, L., Nevill, S. and Griffith, J. (2006), Profile of Undergraduates in U.S. Postsecondary Education Institutions: 2003-04: With a Special Analysis of Community College Students (NCES 2006184), US Department of Education: National Center for Education Statistics, Washington, DC.

Madaus, J.W. and Shaw, S.F. (2006), "Disability services in postsecondary education: Impact of IDEA 2004", Journal of Developmental Education, Vol. 30 No. 1, pp. 12-21.

Meyerson, D.A., Grant, K.A., Carter, J.S. and Kilmer, R.P. (2011), "Posttraumatic growth among children and adolescents: a systematic review", Clinical Psychology Review, Vol. 31 No. 6, pp. 949-964, doi: 10.1016/j.cpr.2011.06.003.

Naidoo, P. (2006), "Potential contributions to disability theorizing and research from positive psychology", Disability and Rehabilitation, Vol. 28 No. 9, pp. 595-602, doi: 10.1080/00222930500219027.

Oaksford, K., Frude, N. and Cuddihy, R. (2005), "Positive coping and stress-related psychological growth following lower limb amputation”, Rehabilitation Psychology, Vol. 50 No. 3, pp. 266-277, doi: 10.1037/0090-5550.50.3.266.

Pollard, C. and Kennedy, P. (2007), "A longitudinal analysis of emotional impact, coping strategies and post-traumatic psychological growth following spinal cord injury: a 10-year review", British Journal of Health Psychology, Vol. 12 No. 3, pp. 347-362, doi: 10.1348/135910707X197046.

Raue, K. and Lewis, L. (2011), Students With Disabilities at Degree-Granting Postsecondary Institutions: First look, National Center for Education Statistics, U.S. Department of Education, Washington, DC, NCES 2011-018.

Salick, E.C. and Auerbach, C.F. (2006), "From devastation to integration: adjusting to and growing from medical trauma”, Qualitative Health Research, Vol. 16 No. 8, pp. 1021-1037, doi: 10.1177/ 1049732306292166.

Seidman, I. (2006), Interviewing as Qualitative Research, Teachers College Press, New York, NY.

Seligman, M.E.P. and Csikszentmihaly, M. (2014), "Positive psychology: an introduction", in Csikszentmihalyi, M. (Ed.), Flow and the Foundations of Positive Psychology: The Collected Works of Mihaly Csikszentmihalyi, Springer, New York, NY, pp. 279-298.

Shakespeare, T. (2013), "The social model of disability", in Davis, L.J. (Ed.), The Disability Studies Reader, Routledge, New York, NY, pp. 214-221.

Shessel, I. and Reiff, H.B. (1999), "Experiences of adults with learning disabilities: positive and negative impacts and outcomes", Learning Disability Quarterly, Vol. 22 No. 4, pp. 305-316.

Sniatecki, J.L., Perry, H.B. and Snell, L.H. (2015), "Faculty attitudes and knowledge regarding college students with disabilities", Journal of Postsecondary Education and Disability, Vol. 28 No. 3, pp. 259-275.

Snyder, T.D., de Brey, C. and Dillow, S.A. (2016), Digest of Education Statistics 2014 (NCES 2016-006), National Center for Education Statistics, Institute of Education Sciences, U.S. Department of Education, Washington, DC. 
Stodden, R.A., Whelley, T., Chang, C. and Harding, T. (2001), "Current status of educational support to students with disabilities in postsecondary education", Journal of Vocational Rehabilitation, Vol. 16 No. 3, pp. 189-198.

Weitzner, E., Surca, S., Wiese, S., Dion, A., Roussos, Z., Renwick, R. and Yoshida, K. (2011), "Getting on with life: positive experiences of living with a spinal cord injury", Qualitative Health Research, Vol. 21 No. 11, pp. 1455-1468, doi: 10.1177/1049732311417726.

\section{Corresponding author}

Jessica L. Sniatecki can be contacted at: jsniatecki@brockport.edu

For instructions on how to order reprints of this article, please visit our website:

www.emeraldgrouppublishing.com/licensing/reprints.htm

Or contact us for further details: permissions@emeraldinsight.com 